\title{
Relación entre la comunicación interna y la administración de la controversia pública
}

Recibido: 20 de noviembre de 2014

Aceptado: 29 de junio de 2015

Publicado: 30 de octubre de 2015
Enrique Elías Villanueva

leliasv@usmp.pe

Universidad de San Martín de Porres (Perú)

\begin{abstract}
Resumen: El objetivo principal de nuestra investigación es conocer de qué manera la comunicación interna se relaciona con la administración de la controversia en los colaboradores de un municipio ubicado en Lima Norte. En el proceso de investigación establecimos la relación entre el tratamiento de los mensajes y la decodificación de los colaboradores, así como la relación entre la credibilidad de la fuente y la empatía generada en el público interno. Finalmente determinamos la relación entre la comunicación bidireccional y el entendimiento mutuo entre los colaboradores. Para elaborar nuestro estudio hemos elegido el diseño no experimental, el tipo de investigación es aplicativa y de nivel descriptivo correlacional; se ha desarrollado el método inductivo, deductivo, analítico y estadístico. La población está formada por 45 unidades de análisis, colaboradores de una municipalidad de Lima Norte. Por su parte, la muestra estuvo formada por 30 unidades de análisis.
\end{abstract}

Palabras claves: Administración de la controversia, comunicación, comunicación bidireccional, comunicación interna, consenso, contenido del mensaje, credibilidad, empatía, mensaje, públicos internos, Relaciones Públicas.

\begin{abstract}
The main objective of our research is to understand how internal communication relates to the management of public controversy in employees of a municipality located in Lima. In the research process we established the relationship between message handling and decoding of employees, as well as the relationship between source credibility and empathy generated in the internal public. Finally, we determined the relationship between the bidirectional communication and mutual understanding among the partners. To develop this study we have chosen the non-experimental design, applicative research is correlational and descriptive level; it has developed inductive, deductive, analytical and statistical method. The population consists of 45 units of analysis, employees of a municipality of Lima. For its part, the sample consisted of 30 units of analysis.
\end{abstract}


Key words: Management of Public Controversy, Communication, Bidirectional Communication, Internal Communication, Consensus, Message Content, Credibility, Empathy, Message, Internal Audiences, Public Relations.

\section{Introducción}

El presente artículo es resultado de una investigación realizada en un municipio limeño y nos permite conocer de qué manera la comunicación interna se relaciona con la administración de la controversia pública en los gobiernos municipales. Para conseguir nuestro objetivo, hemos aplicado la técnica de la encuesta, logrando respuestas valiosas que servirán a quienes en el futuro deseen ejercer las Relaciones Públicas. Asimismo, la revisión de la literatura sobre el tema nos ayudó a presentar un sustento teórico significativo.

La revisión de la bibliografía sobre el tema nos ha permitido observar la importancia que deberían darle las organizaciones a la comunicación con sus públicos, especialmente con los públicos internos o colaboradores. Más aun en el caso de instituciones públicas. Esto con la finalidad de conseguir un impacto positivo ya sea en términos de identidad, compromiso o en actitudes a favor de la organización, reduciendo la aparición de posibles conflictos o situaciones de crisis que afecten el desarrollo armónico de las actividades institucionales.

Podemos afirmar que existen grandes diferencias en la manera en que las comunicaciones son abordadas en las diversas instituciones públicas de nuestro país. Algunas planifican sus estrategias y tácticas comunicacionales o ponen la comunicación en manos de relacionistas públicos profesionales, mientras que otras no le dan al tema la importancia que merece, dejándolas casi al azar o en manos de personal no calificado, lo que resulta contraproducente y dañino para la organización.

Lamentablemente, en la mayoría de casos, la teoría no encuentra reflejo en la práctica, donde observamos poco esfuerzo y escasa creatividad al momento de aplicar o ejecutar la comunicación interna a fin de generar algún tipo de impacto significativo en los colaboradores, además de reducir el rumor y satisfacer la legítima necesidad de los colaboradores de estar informados sobre lo que ocurre en la institución. Por otro lado, es apreciable el aporte de estudiosos de las RR. PP. latinoamericanos, quienes han contribuido de manera entusiasta y significativa al tema de la administración de la controversia pública mediante valiosas investigaciones, los cuales no sólo incrementan el material bibliográfico de consulta, sino que brindan un fundamento teórico, metodológico y axiológico fundamental para la actividad de esta apasionante profesión.

Es en el sector público donde este tema se torna relevante. Es en las municipalidades donde muchas veces se suman (a los problemas de esfuerzo y poca creatividad ya mencionados) la falta de apoyo de la alta dirección, los escasos recursos económicos disponibles y la incomprensión de lo que son o no son las RR. PP. Así, consideramos que en la práctica de las RR. PP. la administración de la controversia pública y la construcción del consenso se han 
constituido en pilares fundamentales del ejercicio profesional, cuyo principal objetivo será desarrollar comunicaciones fluidas y de doble sentido entre autoridades y colaboradores para lograr el entendimiento mutuo.

En un mundo en permanente conflicto, las RR. PP. se presentan como la ciencia y el arte capaz de tender puentes de comprensión a través de la comunicación y la construcción de relaciones humanas sólidas y fraternales. De esta forma, desde la organización se puede comenzar a construir una sociedad donde impere la comprensión entre los seres humanos.

\section{La generación de significados y la comunicación interna}

De acuerdo con la etimología, el término “comunicación” proviene del latinismo comunicatio, el cual tiene su raíz en el sustantivo comunico, que significa ser parte o participar de algo común (Com, 2011: 7). En este sentido, la comunicación "implica algún tipo de relación o de unión entre dos partes, que se conectan o se corresponden entre sí de algún modo" (Ballenato, 2013: 37). Consideramos a la comunicación como un proceso dinámico entre actores sociales que tienen como objetivo construir puentes de entendimiento entre quienes participan de dicho proceso.

Como todo proceso, la comunicación no se presenta como un hecho súbito e inesperado, sino que es un suceso continuo que se desarrolla en un espacio y tiempo determinados, los cuales afectan el proceso comunicativo. Son cambiantes también las circunstancias personales y sociales de los interlocutores. De otro lado, en cuanto al término "interno", se refiere a la orientación o destino de la comunicación dirigida específicamente al público interno de cualquier organización. Black (2004) sostiene que los públicos internos son sus empleados, incluyendo a los de tiempo parcial, directivos, practicantes, dirigentes sindicales, así como a los directivos y empleados de las filiales, sean del país o del extranjero. Por lo tanto, podemos considerar como público interno a todo el conjunto de personas que hacen parte de una organización, quienes además están directamente vinculados a esta. En algunos casos se incluyen también a contratistas, proveedores y distribuidores.

Definimos a la comunicación interna como el conjunto de mensajes dirigidos a los colaboradores y clientes internos. Brandolini, González y Hopkins (2009: 25) la definen como la comunicación "específicamente dirigida al público interno, al personal de una empresa, a todos sus integrantes y que surge a partir de generar un entorno productivo armonioso y participativo". Por lo tanto, la posibilidad de lograr esta comunicación interna gira alrededor de las relaciones humanas armónicas que se van desarrollando. Incluimos (como parte de este tipo de comunicación) a las herramientas, instrumentos y técnicas que buscan favorecer el diálogo y la comprensión. Entre sus beneficios, podemos decir que la comunicación interna permite que los colaboradores se sientan parte activa de la organización, incrementando su participación y favoreciendo la aceptación de iniciativas, impulsándolos hacia la integración, motivación y desarrollo personal, volviéndose "una nueva y efectiva herramienta de gestión que mejora la competitividad organizacional y el clima de trabajo (ibídem: 7). 
Se afirma que la acción comunicacional es considerada como una de las principales funciones de las RR. PP. en cuanto permite a la organización mantener la coordinación entre sus distintas partes y alcanzar así su característica esencial: ser un sistema que funcione adecuadamente. En tal sentido, el Colegio Profesional de Relacionistas Públicos del Perú (2015), en sus normas legales, señala que la comunicación es un medio substancial de su actividad, orientado a la integración social y humana de las organizaciones con sus públicos y (a través de una visión interdisciplinaria) ayuda a construir relaciones equilibradas y armoniosas con dichos públicos en la obtención de sus respectivos objetivos. Recordemos que lo acontecido en el entorno laboral será constantemente interpretado por los colaboradores. Es así, que la acción comunicacional debe ser parte de las políticas de gestión y las estrategias propias de la organización, lo que da lugar al concepto de "comunicación estratégica".

Es posible clasificar la comunicación interna de dos maneras diferentes: a) según la dirección de los mensajes; y b) según el origen de la información. En la primera se habla de comunicación descendente, ascendente y transversal u horizontal. . En la segunda categoría nos referimos a comunicación formal e informal. Brandolini, González y Hopkins (2009: 34-35) explican que la formal es "una forma de comunicación que aborda temas laborales principalmente. Es planificada, sistemática y delineada por la organización", mientras que la informal es "una forma de comunicación en la que se abordan aspectos laborales, que no circula por los canales formales".

La comunicación informal puede ser contraproducente en cuanto puede crear un ambiente negativo entre el personal, ya que muchas veces gozan de una alta credibilidad, aunque no se pueda comprobar su veracidad ni identificar la fuente original. En este sentido, Black (2004) advierte que una buena manera de combatir la amenaza del rumor es mantener informados a nuestros colaboradores, de la mejor forma y en el tiempo oportuno.

La importancia de la comunicación interna destaca cuando analizamos su rol dentro de la organización a la luz de la teoría del "interaccionismo simbólico". Sabemos que los colaboradores desarrollan una estrecha relación con su organización. Al asimilar la cultura organizacional, se genera una manera particular de interpretar los mensajes de la alta dirección y todo tipo de elemento o circunstancia a la cual se le puede dar valor de significado. Las personas se relacionan con los objetos de su entorno (según su interacción con otros individuos) y desde los significados que dichos objetos y personas tienen para ellos mismos.

Los significados se generan a partir de los procesos de interacción social y de comunicación. Entendemos, que la comunicación se torna en un aspecto fundamental, tanto en la constitución del individuo como en la producción social de sentido. De esta manera, los colaboradores siguen un proceso de selección, organización, reproducción y transformación de significados en los procesos interpretativos según sus expectativas, intereses y proyección social al interior de la organización a la cual pertenecen. En el entorno social, la organización funciona como un sistema de significados en la que los colaboradores irán desarrollando expectativas sobre su propia conducta y la de los demás.

La mencionada teoría, propuesta por Mead y Blumer, tiene aún una gran vigencia y sirve como sustento teórico a diversos trabajos dentro de las ciencias sociales. Según Fernández 
y Galguera (2009: 167), "mediante la interacción permanente, vamos construyendo el sentido de las situaciones sociales de la vida cotidiana". Esta teoría nos plantea también una correspondencia entre persona, entorno social y cultura, la misma que se manifiesta en el universo simbólico que permite la comunicación y el sentido (o significado) que se le da a todo aquello que pueda ser considerado como mensaje, tanto los instrumentos mismos como los mensajes formales dentro de una organización (cartas, informes, avisos) y todo aquello que de una u otra manera puede terminar significando algo (espacios, trato, colores, horarios, uniformes, situaciones, momentos, etc.)

Por tanto, para incrementar la comprensión entre las partes y reducir los malos entendidos, todo lo relacionado con la comunicación interna ha de ser considerado una herramienta útil. Además, la organización debe procurar estar siempre dispuesta al diálogo y abierta al consenso puesto que la cultura organizacional es la que determina en gran medida la comunicación interna. El esfuerzo, en este sentido, deberá ser permanente para construir relaciones y vínculos sólidos, fortalecer el compromiso de los colaboradores y lograr el entendimiento mutuo.

\section{Importancia del tratamiento del mensaje para permitir una correcta decodificación}

Un error muy común cada vez que deseamos construir un mensaje y pretender que nos entiendan es codificarlo según lo que consideramos efectivo como emisores, sin saber ni conocer de qué manera este será interpretado por nuestro receptor. La selección de elementos (palabras, colores, formas, etc.), la sintaxis empleada (disposición o relación de unos signos con otros) y lo que cada signo termina por significar en la mente de nuestros receptores son aspectos importantes de lo que llamamos "tratamiento del mensaje".

Es necesario entender primero qué es el mensaje. Berlo (2004) lo define como una conducta física que expresa el propósito de la fuente. El mensaje es entonces translación de ideas (imágenes, opiniones, sentimientos, etc.) e intenciones codificadas mediante un agregado de símbolos sistematizados. A este proceso de convertir el propósito de la fuente en mensaje se le llama “encodificar". En síntesis, el mensaje es aquello que la fuente desea hacer conocer a sus receptores y que precisa ser colocado en un código común a ambos (emisor y receptor). Es por tanto indispensable tener en cuenta los elementos, la estructura, el código y el contenido del mensaje.

Los elementos o unidades forman parte del mensaje y tienen que ser integradas u ordenadas. A esta organización se le conoce como estructura: por ejemplo, en el caso de la palabra "tesis", cada una de las letras que la conforman serían las unidades o elementos y el orden (determinado por el código) es la estructura. Ahora bien, la palabra "aula" puede ser un elemento de universidad. Pero, a su vez, es una estructura si consideramos como elementos términos como "carpetas", "proyector", "pizarra", etc. Por lo tanto, unidades y estructuras dependerán del nivel de análisis del mensaje. Por ese motivo, la estructura es fundamental en tanto permite la correcta interpretación del mensaje. 
En cuanto al código, podemos afirmar que es el conjunto de instrucciones o reglas para disponer y ordenar las unidades. Al descubrir las formas sistémicas (donde se organiza un conjunto de elementos) nos aproximamos al conocimiento del código. Por ejemplo, la lengua, la música y casi toda forma de expresión artística implican un código. Aprendemos el correcto empleo de un código mediante su uso al interior del grupo social al cual pertenece. Los miembros de un grupo pueden comunicarse, ya que tienen en común un conjunto de códigos apropiados para las diferentes circunstancias sociales en las que se interrelacionan. Por tal razón, podemos afirmar que existe una relación muy estrecha entre código y cultura.

Una vez considerado todo lo relativo al código, debemos pensar en el contenido. Este es el material del mensaje, el cual expresa el propósito de la fuente y que puede estar formado por ideas, afirmaciones o juicios. Es decir, toda la información que la fuente proporciona al receptor. (Berlo, 2004: 48-53). La selección del contenido es una tarea delicada. Es necesario analizar la información para determinar qué es lo importante, pero también es básico conocer al receptor y entender cuáles son sus intereses. Según Ballenato (2013: 58), “algunas personas tienen cierta dificultad para seleccionar lo esencial del contenido y transmitirlo de una forma estructurada pero breve. Así, se pierden en largas disertaciones y explicaciones que animan al receptor a desconectar en cuanto tienen ocasión".

En esta tarea, el relacionista público deberá exigirse de manera permanente. La experiencia (y sobre todo la evaluación permanente de los resultados) le ayudará a elegir mejor los contenidos. Por estas razones, entendemos que el tratamiento del mensaje incide, de manera relevante, en la correcta decodificación del mensaje. Esto último implica una diversidad de acciones y habilidades. Es necesario tomar en cuenta también las circunstancias que rodean el acto comunicativo. Berlo (2004: 54) indica que en la decodificación "hacemos inferencias en cuanto al propósito de la fuente, a sus habilidades comunicativas, sus actitudes hacia nosotros, su grado de conocimiento y su posición. Tratamos de establecer qué tipo de persona puede haber emitido esta clase de mensaje".

Cada vez que el receptor se enfrenta a un mensaje trata de comprender qué es lo que pretende la fuente; calcula aspectos como el vocabulario, las actitudes (hacia al emisor, hacia el tema y hacia sí mismo), si es una fuente experta en el tema, cuál es su propio conocimiento del tema, las circunstancias, etc. Esta es una etapa importante del proceso comunicativo y una tarea que (aunque le compete básicamente al receptor) exige una correcta planificación del emisor. La decodificación es un proceso en el cual el receptor descifra el mensaje de la fuente gracias a su conocimiento del código y a sus habilidades sensoriales.

En este proceso se deben considerar diversos aspectos psicoafectivos y psicosociales que influyen en los interlocutores y determinan el sentido de la comunicación. Según Niño (2002) todo proceso comunicativo se reduce a dos grandes fases: la producción y la comprensión. Comprender el mensaje es descubrir el propósito de la fuente y deducir la información que dicho mensaje contiene. El subproceso de comprensión del mensaje involucra la recepción, decodificación e interpretación del mensaje según el código elegido por el emisor, el campo de experiencia y el contexto comunicacional. 
Tras la explicación del código y su importancia, nos ocuparemos del campo de experiencia al cual podemos definir como "espacio común". Schramm afirma que se llama así "al conjunto de conocimientos, opiniones, actitudes, ideología y cultura, en general, resultado de las experiencias de la vida, lo cual condiciona, de alguna manera, los procesos de comunicación entre las personas" (ápud Niño, 2013: 38). Las enseñanzas adquiridas en la escuela a la que asistimos, lo que aprendimos en la familia, las películas que hemos visto, las charlas que compartimos con amigos o desconocidos, los patrones culturales aprendidos, todo forma parte de ese campo de experiencia que nos permite construir significados comunes que posibilitan la comprensión entre interlocutores.

El contexto se refiere al conjunto de situaciones en las que está inmerso el acto comunicativo. Es decir, las condiciones personales y sociales que experimentan los interlocutores, el espacio físico, las circunstancias, etc., y que definen el tema o los temas a tratar, el grado de formalidad, los niveles de interacción y otros aspectos que pueden influir en el éxito o no de la comunicación. Según Niño (2002: 49) nos permite "solucionar un conflicto de ambigüedad, anomalía u otra irregularidad semántica". Se precisa la existencia de un contexto "extraverbal" y uno "verbal". Este último atañe a las circunstancias o condiciones lineales de los enunciados, es decir, se centra en el diálogo.

Así, todos los factores del tratamiento del mensaje y los condicionantes para una adecuada decodificación inciden en algo importante: el significado o los significados que emisor y receptor comparten. Guiraud sostiene que "el significado es una construcción mental" (ibidem: 51). Los significados se encuentran en las personas, no en las palabras. Se van aprendiendo por medio de la experiencia y surgen o se desarrollan en la cultura de cada grupo social.

Para comprender mejor la definición de significado es necesario recordar qué es el signo. Se lo define como todo elemento que permite referirnos a algo distinto de sí mismo. Para algunos es una entidad diádica formada por un significante (parte material y perceptible) y por un significado (parte inmaterial, concepto o idea asociada al significante empleado). Para autores como Peirce, el signo es triádico, constituido por el representamen o signo, el objeto y el interpretante o conjunto de ideas asociadas al signo o representamen.

El proceso que permite esta relación entre significante y significado se llama "semiosis". Consideramos como significantes no solo palabras sino cualquier elemento, más allá de la materia que lo constituye y que puede servir para transmitir un significado, Debemos precisar que por concepto no nos referimos solamente a la definición que aparece en los diccionarios, sino a todo aquello que genera en el receptor la percepción del significante. Incluyendo ideas, emociones o conductas. La cultura organizacional le asignará un significado particular a todo elemento convirtiéndolo en signo y todo signo generará conductas e ideas en los colaboradores. Conducta e ideas que nos conducen a la comprensión o a la controversia.

En las encuestas aplicadas entre los colaboradores de un municipio de Lima encontramos que el inadecuado tratamiento del mensaje dificulta la correcta decodificación del mensaje. 
Figura 1: Resultados de encuestas - colaboradores municipio.

\begin{tabular}{|c|c|c|c|c|c|}
\hline & $\begin{array}{l}\text { TOTALMENTE } \\
\text { DE ACUERDO }\end{array}$ & $\begin{array}{l}\text { PARCIALMENTE } \\
\text { DE ACUERDO }\end{array}$ & INDECISO & $\begin{array}{l}\text { PARCIALMENTE } \\
\text { EN DESACUERDO }\end{array}$ & $\begin{array}{c}\text { TOTALMENTE EN } \\
\text { DESACUERDO }\end{array}$ \\
\hline $\begin{array}{l}\text { El lenguaje empleado por la alta } \\
\text { gerencia en sus mensajes es de } \\
\text { uso común o conocido por usted. }\end{array}$ & $23.3 \%$ & $50.0 \%$ & $26.7 \%$ & $0.0 \%$ & $0.0 \%$ \\
\hline $\begin{array}{l}\text { La información de la alta } \\
\text { dirección llega oportunamente } \\
\text { a usted y a los demás } \\
\text { colaboradores. }\end{array}$ & $0.0 \%$ & $13.3 \%$ & $53.3 \%$ & $33.3 \%$ & $0.0 \%$ \\
\hline $\begin{array}{l}\text { La información y los mensajes } \\
\text { son de fácil acceso para usted. }\end{array}$ & $3.3 \%$ & $23.3 \%$ & $33.3 \%$ & $40.0 \%$ & $0.0 \%$ \\
\hline $\begin{array}{l}\text { Recibe usted información de } \\
\text { interés por parte de la institución. }\end{array}$ & $6.7 \%$ & $16.7 \%$ & $36.7 \%$ & $40.0 \%$ & $0.0 \%$ \\
\hline $\begin{array}{l}\text { La información recibida le } \\
\text { permite tener un conocimiento } \\
\text { oportuno de las actividades que } \\
\text { realizará la institución. }\end{array}$ & $0.0 \%$ & $56.7 \%$ & $36.7 \%$ & $6.7 \%$ & $0.0 \%$ \\
\hline $\begin{array}{l}\text { La alta dirección difunde } \\
\text { mensajes claros y sencillos. }\end{array}$ & $3.3 \%$ & $20.0 \%$ & $40.0 \%$ & $36.7 \%$ & $0.0 \%$ \\
\hline $\begin{array}{l}\text { Considera que la municipalidad } \\
\text { utiliza palabras fáciles de } \\
\text { comprender. }\end{array}$ & $20.0 \%$ & $33.3 \%$ & $46.7 \%$ & $0.0 \%$ & $0.0 \%$ \\
\hline $\begin{array}{l}\text { Las imágenes facilitan la } \\
\text { comprensión de los mensajes } \\
\text { difundidos por los encargados de } \\
\text { la comunicación interna. }\end{array}$ & $20.0 \%$ & $3.3 \%$ & $56.7 \%$ & $20.0 \%$ & $0.0 \%$ \\
\hline $\begin{array}{l}\text { El estilo de redacción de } \\
\text { los mensajes permite que se } \\
\text { entiendan con claridad. }\end{array}$ & $10.0 \%$ & $6.7 \%$ & $60.0 \%$ & $23.3 \%$ & $0.0 \%$ \\
\hline $\begin{array}{l}\text { Los encargados de la } \\
\text { comunicación interna elijen } \\
\text { los medios de comunicación } \\
\text { apropiados para el acceso y } \\
\text { comprensión de los mensajes. }\end{array}$ & $10.0 \%$ & $13.3 \%$ & $43.3 \%$ & $33.3 \%$ & $0.0 \%$ \\
\hline
\end{tabular}

Fuente: Elaboración propia.

Podemos notar que en cuanto a los elemento o unidades (palabras e imágenes) empleados en el tratamiento del mensaje, los colaboradores afirman que son fáciles de comprender, el problema parece estar en otros aspectos. La información no siempre llega de manera oportuna, el acceso a la información no es el mejor y esto porque no se eligen los medios más adecuados. La información recibida no siempre es de interés para los colaboradores, a pesar que les permite tener un conocimiento mayor de las actividades realizadas por la institución. Asimismo, es necesario mejorar el estilo de redacción.

\section{La credibilidad de la fuente en la generación de empatía}

Es bastante conocido el aporte de Hovland: sus conclusiones señalan la importancia de la credibilidad de la fuente para lograr la eficacia persuasiva en el acto comunicativo (ápud 
Otero, 1997). En ese sentido, un mismo mensaje emitido por una fuente digna de crédito y alta confiabilidad ofrece mejores resultados. Nothstine (1992) hace referencia a la credibilidad (que surge de ser percibidos como interlocutores competentes, honestos, dinámicos, preocupados por las necesidades y valores de nuestro público y no solo por las nuestras), como la cualidad más importante que podemos tener como comunicadores. Podemos establecer entonces que la credibilidad genera la confianza necesaria para aceptar los mensajes. Esto se debe a que las relaciones humanas se basan en la confianza, la cual fortalece la comunicación.

Esta confianza en la fuente surge, en primer lugar, de la coherencia entre el decir y el actuar. Cuando se percibe coherencia en la fuente, los receptores están más dispuestos a aceptar las propuestas que se les plantea y es factible ganar su predisposición o buena voluntad hacia los objetivos organizacionales. En segundo lugar, la confianza se da cuando se reconoce el conocimiento que la fuente o emisor tienen en el tema tratado. Barquero y Barquero (2005) afirman que no es importante si el informador (fuente) pertenece o no a la organización, sino que este sea reconocido como una autoridad o especialista en la materia que trata.

Para Pereira y Flores (2010: 23), "la verdadera confianza no es gratuita, sino resultado de la experiencia; es decir que nosotros confiamos en las personas que ya anteriormente han demostrado una conducta honesta y responsable". Los públicos evalúan de manera permanente nuestra conducta y no gustan de percibir divergencias entre lo que se expresa y lo que se hace. Simon (2009) nos recuerda que si el receptor considera que la fuente tiene algo que ganar, tendrá menos probabilidades de ser confiable. El mismo mensaje se juzga de manera más favorable cuando es emitido por un comunicador de gran credibilidad y si el tema es de una naturaleza poderosamente técnica, se confiará más en aquellos a quienes se les considera expertos.

La confianza es importante para generar empatía. Cabe destacar que el receptor tendrá que hacer un esfuerzo para entender lo que la fuente quiere comunicarle. Y la pregunta es ¿por qué tendría que hacerlo? Una de sus motivaciones será la empatía que sienta por la fuente o emisor, que en la organización se traducirán como identidad y sentido de pertenencia. Entendemos empatía como la capacidad que tenemos como seres humanos de conectar con otras personas y responder a sus necesidades. Según Goleman (2009: 13) es la "captación de sentimientos, necesidades e intereses ajenos". Comúnmente se la define como "ponerse en los zapatos del otro". Es decir, tratar de juzgar, evaluar o apreciar las cosas desde lo que el otro realmente vive y experimenta. Quien tiene el propósito de comunicar algo debe proponerse comprender el marco de realidad de sus receptores, además de esforzarse en impulsar dicha empatía a fin de lograr disposición y voluntad para la aceptación de los mensajes.

Fomentar la empatía no es fácil. Debemos dejar de lado lo que supuestamente sabemos del receptor y estar dispuestos a mirarlo como si lo hiciéramos por primera vez (Rosenberg, 2006). Es necesario no anticipar respuestas ni juicios sin conocer las necesidades o situación del receptor o sin tener la certeza de haber realizado una interpretación correcta del propósito de nuestros destinatarios. La empatía es el paso previa a la completa interacción (objetivo ideal de la comunicación) según Berlo (2004: 94-113), quien plantea cuatro niveles: 
- “Interdependencia física por definición: basta solo la presencia del receptor para que la fuente emita información sin preocuparle los resultados.

- Interdependencia de acción-reacción: es importante la respuesta que emite el receptor. Este feedback o realimentación va determinando la conducta de los interlocutores.

- Interdependencia de las expectativas o empatía: nivel donde se llega a anticipaciones sobre los estados psicológicos entre interlocutores. Así, atendemos y seleccionamos los mensajes según las imágenes que hemos desarrollado mutuamente.

- Interacción: es un proceso de aceptación (apropiación, ocupación o posesión) recíproca de roles entre fuente y receptor en los que se establece la comunicación plena".

El citado autor indica que existen dos teorías que explican la empatía. La teoría de la empatía basada sobre la inferencia. La cual indica que al observar nuestra conducta física y relacionarla simbólicamente con nuestros estados psicológicos internos adquirimos significados para esa conducta. De tal manera, una conducta similar observada en otra persona deberá tener el mismo significado.

La segunda es la teoría de la empatía basada en el desempeño del rol, donde se considera que las personas desarrollan conductas empáticas basándose en conductas físicas observables en otros. Será importante primero haber desarrollado el concepto de sí mismo. En un principio estas conductas carecen de significado. Pero, las conductas que se van ejecutando son recompensadas. Por tal razón, la persona las retiene. A medida que obtiene los resultados esperados, aumenta la ejecución de la conducta que mejores recompensas les ofrece.

Por ejemplo, en las organizaciones, los nuevos colaboradores tienden a imitar lo que hacen sus superiores o la conducta de los empleados más antiguos. Poco a poco van asignándole significados a las conductas observadas e imitadas, construyendo un universo simbólico que define su realidad. Es decir, se definen los signos que emplean, la manera de utilizarlos y su sentido. Así, podemos concluir que ser empático significa ser comprensivos. Tratar de evaluar cada situación y observar cada aspecto de la comunicación desde la perspectiva de nuestro interlocutor. Esto se logra, respetándolo, así como considerando sus sentimientos, habilidades, necesidades y propósitos.

Los estudios aplicados en relación a la credibilidad y la empatía arrojan los siguientes resultados: 
Figura 2: Resultados de encuestas - colaboradores municipio.

\begin{tabular}{|c|c|c|c|c|c|}
\hline & $\begin{array}{l}\text { TOTALMENTE } \\
\text { DE ACUERDO }\end{array}$ & $\begin{array}{l}\text { PARCIALMENTE } \\
\text { DE ACUERDO }\end{array}$ & INDECISO & $\begin{array}{l}\text { PARCIALMENTE } \\
\text { EN DESACUERDO }\end{array}$ & $\begin{array}{c}\text { TOTALMENTE } \\
\text { ENDESACUERDO }\end{array}$ \\
\hline $\begin{array}{l}\text { La confianza en la información } \\
\text { recibida genera mayor } \\
\text { credibilidad en la institución. }\end{array}$ & $3.3 \%$ & $20.0 \%$ & $60.0 \%$ & $16.7 \%$ & $0.0 \%$ \\
\hline $\begin{array}{l}\text { El conocimiento de los temas } \\
\text { tratados por parte de los } \\
\text { voceros aumenta la credibilidad } \\
\text { en la municipalidad. }\end{array}$ & $10.0 \%$ & $20.0 \%$ & $50.0 \%$ & $20.0 \%$ & $0.0 \%$ \\
\hline $\begin{array}{l}\text { Confía usted en los encargados } \\
\text { de la comunicación interna. }\end{array}$ & $6.7 \%$ & $20.0 \%$ & $60.0 \%$ & $13.3 \%$ & $0.0 \%$ \\
\hline $\begin{array}{l}\text { Cree usted que la institución } \\
\text { emite información objetiva. }\end{array}$ & $10.0 \%$ & $10.0 \%$ & $46.7 \%$ & $33.3 \%$ & $0.0 \%$ \\
\hline $\begin{array}{l}\text { La institución emite mensajes } \\
\text { coherentes o acordes con sus } \\
\text { políticas y valores. }\end{array}$ & $3.3 \%$ & $16.7 \%$ & $46.7 \%$ & $33.3 \%$ & $0.0 \%$ \\
\hline $\begin{array}{l}\text { Tiene usted una alta } \\
\text { identificación con las normas } \\
\text { institucionales. }\end{array}$ & $13.3 \%$ & $10.0 \%$ & $30.0 \%$ & $43.3 \%$ & $3.3 \%$ \\
\hline $\begin{array}{l}\text { Tienen usted y sus compañeros } \\
\text { una alta filiación con los } \\
\text { valores que promueve la } \\
\text { municipalidad. }\end{array}$ & $20.0 \%$ & $26.7 \%$ & $50.0 \%$ & $3.3 . \%$ & $0.0 \%$ \\
\hline $\begin{array}{l}\text { El contenido de los mensajes } \\
\text { difundidos por la alta dirección } \\
\text { responde solo a los intereses de } \\
\text { la institución. }\end{array}$ & $10.0 \%$ & $10.0 \%$ & $46.7 \%$ & $33.3 \%$ & $0.0 \%$ \\
\hline $\begin{array}{l}\text { La información difundida } \\
\text { considera las necesidades de } \\
\text { los colaboradores. }\end{array}$ & $0.0 \%$ & $26.7 \%$ & $50.0 \%$ & $23.3 \%$ & $0.0 \%$ \\
\hline $\begin{array}{l}\text { Está dispuesto a aportar tiempo } \\
\text { y esfuerzo a fin de lograr los } \\
\text { objetivos institucionales. }\end{array}$ & $16.7 \%$ & $6.7 \%$ & $36.7 \%$ & $40.0 \%$ & $0.0 \%$ \\
\hline
\end{tabular}

Fuente: Elaboración propia.

Teniendo en cuenta que la credibilidad es una de las cualidades más importantes que un comunicador puede poseer, más aún si pretende generar empatía en sus receptores, este cuadro nos permite observar los niveles de confianza que muestran los colaboradores. Lo lamentable, es el número de indecisos ante cada respuesta. Esto respondería a que los colaboradores perciben falta de objetividad en los mensajes. La baja filiación de colaboradores con las normas puede ser también un tema preocupante, aunque sí existe una alta filiación con los valores institucionales. Es recomendable que se aproveche la credibilidad de los voceros y la confianza en la información recibida para fortalecer el diálogo y el debate. 


\section{Motivar la comunicación bidireccional para lograr el entendimiento mutuo}

Una de las principales características de todo proceso de comunicación es la bidireccionalidad. Es decir, que los mensajes fluyan desde la fuente hacia el receptor y viceversa. Toda organización ha de establecer los canales necesarios no sólo para hacer llegar sus mensajes a los públicos, sino también para permitir que estos públicos se manifiesten y puedan realimentarlas dándoles a conocer su opinión y su sentir. Los canales de comunicación (ascendentes y descendentes) han de permitir la emisión y recepción de mensajes en ambos sentidos.

En ese sentido, comunicarse no sólo implica que el emisor sepa decir, sino también que sepa escuchar. Si realmente deseamos comunicarnos, debemos estar atentos a las respuestas y reacciones de nuestros receptores. Todo mensaje que los receptores envían de retorno a la fuente se conoce como realimentación. La realimentación o feedback es uno de los elementos internos del proceso comunicativo. Diez (2011) destaca su importancia cuando nos dice que esta información le permite saber al emisor si su mensaje fue recibido, si ha sido adecuadamente interpretado y si este fue utilizado.

En la comunicación "cara a cara", el emisor puede evaluar las palabras y los aspectos propios de la comunicación no verbal implícitos en la respuesta recibida, tales como los kinésicos (gestos y movimiento corporal), proxémicos (distancias y espacio) y paralingüísticos (tono, ritmo y volumen de la voz). Las organizaciones no deben dejar de evaluar la realimentación de sus públicos. Es recomendable motivar o generar canales adecuados para analizar y evaluar toda la realimentación a fin de conocer el nivel de aceptación e influencia de nuestros mensajes. Si afirmamos que la comunicación es un proceso que se completa con la respuesta del receptor, la realimentación en las organizaciones, como afirma Simon (2009), es el componente propio de las acciones comunicacionales que completa el proceso de las relaciones públicas.

El área de RR. PP. deberá construir un modelo de comunicación que permita el diálogo y que los mensajes se emitan en ambas direcciones, valorando las respuestas de sus receptores. A esto se le conoce como modelo simétrico bidireccional. Grunig y Hunt (2000: 75-104) nos recuerdan que a lo largo de la historia, los profesionales de las relaciones públicas han empleado cuatro modelos de comunicación. Estos son:

- "Modelo de agente de prensa o publicity: el primero en aplicarse. Considera que difundir toda la verdad no es esencial, pues la meta es la manipulación y desinformación. Se caracteriza por el flujo unidireccional de la información pues no toma en cuenta la realimentación.

- Modelo de información pública: continúa primando el flujo unidireccional de la información. Aunque esta se transmite de manera objetiva y no necesariamente para persuadir. Aquí la verdad es importante. 
- Modelo asimétrico bidireccional: el cual considera importante conocer al público; por eso los investigan, aplicando las teorías de las ciencias sociales (por ejemplo la psicología) a fin de conocer las actitudes y las conductas de los públicos, teniendo como objetivo la persuasión científica, para lograr que los receptores adopten el punto de vista de la organización y le brinden su apoyo. Este modelo descubre la utilidad del 'feedback' o realimentación.

- Modelo simétrico bidireccional: aquí los relacionistas públicos son los mediadores entre la organización y sus públicos, la investigación sigue siendo importante, y por lo tanto, se continúan utilizando las teorías y métodos propios de las ciencias sociales; pero, no para saber cómo persuadir a los públicos, sino, para lograr la comprensión mutua. Por esta razón se considera como el mejor de los modelos desde una perspectiva ética. Este es el modelo que hoy debería aplicarse pues representa y encarna al relacionista público moderno".

En cuanto al entendimiento mutuo, al referirnos a la organización y sus públicos, se le considera como uno de los principales objetivos de las RR. PP. La definición de RR. PP. del British Institute of Public Relations que nos presenta Grunig y Hunt (2000: 54) reafirman lo anterior al subrayar "el esfuerzo planificado, deliberado y sostenido para establecer y mantener una comprensión mutua entre una organización y su público". Este entendimiento mutuo, comprensión mutua o consenso va a ser el resultado, en gran medida, de una correcta aplicación de las herramientas de comunicación y del manejo o administración adecuada de la controversia pública al interior de las organizaciones.

Teniendo clara esta idea, es posible interpretar las RR. PP. como una pedagogía del consenso. Este interesante paradigma, propuesto por Solórzano y Pérez Senac, afirma que para conseguir una labor óptima en RR. PP. es necesario considerar a la integración humana como un proceso educativo el cual necesita un método que nos ayude a vencer los obstáculos y límites que no permiten el desarrollo de auténticas relaciones y comunicaciones (Solórzano, 2013). Los citados autores enfatizan la capacidad humana para relacionarnos y comunicarnos, así como el rol destacado de las RR. PP. Además, integran la administración de la controversia pública entre las propuestas teóricas, metodológicas y axiológicas como elemento constitutivo de este paradigma. De esta manera, concluyen lo siguiente:

- “Las RR. PP. tienen como propósito la construcción de vínculos.

- El campo de acción de estas está representado por las organizaciones y los públicos, tanto desde el ámbito relacional, como del ámbito comunicacional.

- Es posible que las RR. PP. alcance la legitimidad de sus acciones comunicacionales gracias a la ética de transparencia que guían sus acciones relacionales. Estas acciones cuentan así con un cuerpo teórico, metodológico y axiológico que las conduce". 
Podemos señalar que las RR. PP. se fundamentan en la confianza mutua entre la organización y sus públicos, teniendo como base el intercambio de información con credibilidad y la conducta ética que legitima sus propuestas. Esta cultura de la confianza ha de ser promovida persistentemente. La bidireccionalidad, promovida desde la alta dirección, evidencia el valor que la organización le da a la interacción con sus públicos, teniendo como meta lograr compromisos en el largo plazo. Dichos compromisos se orientan a la solución de problemas, respetando los intereses de ambas partes y no buscando solo influir en los receptores.

El objetivo es la comprensión consenso o entendimiento mutuo. Esto es posible gracias a la investigación previa que ayuda a conocer la situación de los públicos, así como sus intereses, expectativas y necesidades. Asimismo, se necesita de la buena predisposición de la organización para estar siempre atenta y abierta al diálogo. La sentencia "hacerlo bien y hacerlo saber" (que define en parte las actividad de las Relaciones Públicas) debe tener como referente la ética de las acciones comunicacionales y relacionales, a fin de ratificar, certificar y avalar sus propósitos. Esta coherencia entre comunicación y relación humana aumenta la cultura de confianza, permitiéndonos alcanzar el consenso.

Según Solórzano (2000: 6) "el uso originario del lenguaje está fundamentalmente orientado hacia el entendimiento, frente al cual todas las demás circunstancias se comportan de forma secundaria", haciendo una referencia a los aportes de Habermas quien desarrolla la "teoría de la acción comunicativa". En esta teoría, Habermas (1999) considera al lenguaje como una dimensión constitutiva de la actividad humana. De esta manera se separa de pensadores como Adorno, Horkheimer o Gramsci, esbozando que este tipo de cambio debe darse en un ámbito simbólico o ámbito comunicativo de interacción y entendimiento entre los sujetos, que bien podría ser el de las organizaciones. Considera, además, que la sociedad está hecha de relaciones comunicativas. Por lo tanto, cuando no se utiliza el lenguaje para lograr el entendimiento su fin es parasitario.

Este consenso o entendimiento sólo será posible si la argumentación de los actores sociales cumple ciertas condiciones. En primer lugar, el enunciado que realiza el hablante debe ser comprensible para sus interlocutores. Luego, el hablante tiene que ser confiable. En tercer lugar, la acción pretendida debe ser correcta o afín al marco normativo y, finalmente, la acción del hablante debe corresponder a lo que piensa. De otro lado, es necesario que la acción comunicativa se desarrolle en un espacio ideal en términos de oportunidad de participación en igualdad de condiciones para todos los interlocutores (Garrido, 2015).

Consideramos a las RR. PP. como una actividad profesional orientada a la búsqueda de convergencias. Este consenso o entendimiento mutuo es posible cuando las relaciones humanas y las acciones comunicacionales siguen una perspectiva ética que las orienta a superar la búsqueda de objetivos egoístas y personales y toma en cuenta las necesidades de todos los públicos, considerados como actores sociales. Si la acción relacional está inmersa en una ética y moral adecuadas, entonces legitimarán nuestras acciones comunicacionales. Para ello, el ser humano, en su praxis social, deberá emplear el lenguaje con el propósito principal de lograr el entendimiento mutuo. 
Figura 3: Resultados de encuestas - colaboradores municipio.

\begin{tabular}{|c|c|c|c|c|c|}
\hline & $\begin{array}{l}\text { TOTALMENTE } \\
\text { DE ACUERDO }\end{array}$ & $\begin{array}{l}\text { PARCIALMENTE } \\
\text { DE ACUERDO }\end{array}$ & INDECISO & $\begin{array}{l}\text { PARCIALMENTE } \\
\text { ENDESACUERDO }\end{array}$ & $\begin{array}{c}\text { TOTALMENTE } \\
\text { ENDESACUERDO }\end{array}$ \\
\hline $\begin{array}{l}\text { La institución promueve el } \\
\text { diálogo abierto mejorando la } \\
\text { comunicación bidireccional. }\end{array}$ & $0.0 \%$ & $60.0 \%$ & $33.3 \%$ & $6.7 \%$ & $0.0 \%$ \\
\hline $\begin{array}{l}\text { La institución tiene canales de } \\
\text { comunicación ascendentes que } \\
\text { promueven el diálogo. }\end{array}$ & $3.3 \%$ & $13.3 \%$ & $50.0 \%$ & $33.3 \%$ & $0.0 \%$ \\
\hline $\begin{array}{l}\text { La municipalidad presta } \\
\text { atención a los mensajes que } \\
\text { llegan de sus colaboradores. }\end{array}$ & $6.7 \%$ & $26.7 \%$ & $40.0 \%$ & $26.7 \%$ & $0.0 \%$ \\
\hline $\begin{array}{l}\text { La institución permite y acepta } \\
\text { la realimentación de sus } \\
\text { colaboradores. }\end{array}$ & $6.7 \%$ & $13.3 \%$ & $53.3 \%$ & $26.7 \%$ & $0.0 \%$ \\
\hline $\begin{array}{l}\text { La institución tiene } \\
\text { consideración de las necesidades } \\
\text { de los colaboradores y las } \\
\text { incluyen en los mensajes que } \\
\text { emiten. }\end{array}$ & $0.0 \%$ & $16.7 \%$ & $56.7 \%$ & $26.7 \%$ & $0.0 \%$ \\
\hline $\begin{array}{l}\text { Recibe usted la información } \\
\text { difundida por la municipalidad } \\
\text { con buena voluntad. }\end{array}$ & $13.3 \%$ & $6.7 \%$ & $50.0 \%$ & $30.0 \%$ & $0.0 \%$ \\
\hline $\begin{array}{l}\text { Tiene la oportunidad de } \\
\text { expresarse abiertamente sin } \\
\text { temor a recibir represalias. }\end{array}$ & $10.0 \%$ & $10.0 \%$ & $30.0 \%$ & $46.7 \%$ & $3.3 \%$ \\
\hline $\begin{array}{l}\text { Existe voluntad de proponer } \\
\text { soluciones a los problemas } \\
\text { de comunicación entre la } \\
\text { institución y sus colaboradores. }\end{array}$ & $23.3 \%$ & $20.0 \%$ & $56.7 \%$ & $0.0 \%$ & $0.0 \%$ \\
\hline $\begin{array}{l}\text { Tiene usted una alta } \\
\text { identificación con las políticas } \\
\text { institucionales. }\end{array}$ & $10.0 \%$ & $10.0 \%$ & $56.7 \%$ & $23.3 \%$ & $0.0 \%$ \\
\hline $\begin{array}{l}\text { Entre usted y sus compañeros } \\
\text { de trabajo existen relaciones de } \\
\text { colaboración. }\end{array}$ & $13.3 \%$ & $6.7 \%$ & $46.7 \%$ & $30.0 \%$ & $3.3 \%$ \\
\hline
\end{tabular}

Fuente: Elaboración propia.

Si bien es cierto que los colaboradores manifiestan que la institución promueve el diálogo abierto, es necesario mejorar los canales de comunicación ascendente. Eso ayudaría a demostrar que existe un interés legítimo por atender los mensajes del público interno y por aceptar la realimentación como un elemento fundamental para el entendimiento mutuo, algo que hasta el momento no se está logrando.

Además, los colaboradores señalan que existe el diálogo, pero consideran que esto responde más al interés de la institución y no de sus propias necesidades; por tal razón, se reduce la identificación con las políticas institucionales y disminuyen las relaciones colaborativas entre el público interno. Lo rescatable es que la investigación demuestra que existe el deseo y la voluntad de proponer soluciones. Por lo que se ratifica la necesidad de mejorar los medios de comunicación ascendente. 


\section{La administración de la controversia pública}

En cuanto a administrar podemos relacionarlo con ordenar, dirigir, suministrar o disponer. Así, Correa (2014: 6) arguye que la administración se define como "el proceso de diseñar y mantener un entorno en el que, trabajando en grupos, los individuos cumplan eficientemente objetivos específicos". Es común emplear el término "gestionar" para referirse a "administrar". Hacemos esta aclaración pues al tratar el tema de administración en la controversia pública algunos autores emplean la expresión "gestión de conflictos latentes".

En cuanto a la definición de "controversia", es necesario diferenciarla de la de "conflicto", ya que en muchas oportunidades son términos empleados como sinónimos. Entendemos por controversia el debate o discusión que puede existir entre dos partes con respecto a un tema. En cambio, el conflicto se hace evidente cuando una controversia no ha sido adecuadamente tratada. Así, el conflicto se refiere a lucha, enfrentamiento o problema.

Solórzano y Pirotte (2006) definen controversia como la incompatibilidad de opiniones y pareceres. Una discusión extensa y meticulosa que puede estar oculta, la misma que de no ser administrada adecuadamente puede llegar a convertirse en conflicto. Los citados autores definen el conflicto como "situación extrema. Proceso que comienza cuando una parte percibe en forma cabal que la otra afecta en forma negativa sus intereses" (ibidem: 91). Mientras resulta positivo motivar la controversia en tanto incentiva la generación, desarrollo, evaluación y aplicación de ideas que se presentan como alternativas de acción, debemos evitar el conflicto, pues ocasiona una pugna entre las partes implicadas, provocando las crisis, afectando a la organización de tal manera que, incluso, pueden impedir la consecución de algunos de sus objetivos.

Para referirse a la administración de la controversia pública, autores como Xifra (2009: 7), emplean el anglicanismo issues management o la expresión "gestión de conflictos potenciales", cuya definición reza de la siguiente manera:

"La gestión de conflictos potenciales (GCP, o gestión de temas potencialmente conflictivos: issues management) constituye la aplicación de comunicación entre las organizaciones y sus públicos en un contexto muy específico: la elaboración de las políticas públicas. De ahí que en sus inicios se hablara de public issues management. Sin embargo, al final su desarrollo en ese ámbito ha ofrecido un modelo de actuación aplicable a cualquier problema de relaciones públicas".

De esta manera, se debe valorar la posibilidad de ampliar el rango de actividades de RR. PP. y orientarlas a la labor de escuchar a los públicos para conocerlos, entender sus percepciones y fomentar el diálogo. Se considera a la administración de la controversia pública como una de las principales funciones de la comunicación en el ámbito de las RR. PP. en la actualidad. Esta realidad es planteada por Solórzano (2013), quien nos dice que las RR. PP. no deberían limitarse a la aplicación de técnicas de comunicación, ya que resultan ser más complejas y más amplias. Por tanto, no habrá de restringirse sólo a la imagen de las organizaciones. 
Deben, además, estar al tanto de las actitudes y opiniones que emanan de la discusión sobre temas de interés para los públicos, temas que pueden ser controversiales, a fin de encontrar puntos de convergencia o entendimiento.

Para cumplir adecuadamente esta función, se recomienda aplicar el modelo estratégico propuesto por Xifra (2010), el cual es comparable con el modelo estratégico propio de las RR. PP. que comprende a la organización (su tamaño y recursos) y la complejidad de los problemas por resolver. Se plantean cinco etapas:

- “Identificación de conflictos potenciales: además de identificarlos, se deben clasificar previendo su posible evolución y las probabilidades de impedir que la organización logre sus objetivos. Se ha de considerar la misión, visión, objetivos, plan de acción y operaciones de la organización.

- Fijación de prioridades: es jerarquizar, pues no todos los temas tendrán la misma importancia ni urgencia. Será necesario definir su impacto a corto plazo y si exigen o no una respuesta inmediata.

- Posicionamiento de la organización: esto significa que la organización deberá asumir una postura que consiste en el enfoque del tema y su solución. Para el autor, el posicionamiento exige: la declaración o definición del posible conflictivo, la visión o enfoque de la organización, y la respuesta o solución planteada.

- Implantación de la estrategia: en algunos casos será suficiente con una declaración, en otros se impondrá el desarrollo de todo un plan de acción.

- Evaluación y control: observar y medir los resultados. Es necesario realizar el seguimiento de nuestras acciones, valorar los resultados y decidir las siguientes acciones. Es necesario precisar la evolución del conflicto para determinar su relevancia y prioridad".

El modelo estratégico es un proceso cíclico que exige observar y evaluar la realidad permanentemente. Aplicar los correctivos necesarios y volverlos a evaluar. La administración de la controversia pública saca a la luz temas de interés, incentiva el debate de las partes implicadas y propone soluciones evitando la aparición de conflictos. Recordemos que la comunicación es un proceso que requiere de una planificación cuidadosa, conocer a nuestros receptores y sus intereses y que las fuentes con mayor credibilidad son las que logran mejores resultados.

\section{Conclusiones}

La institución objeto de estudio ha descuidado detalles importantes relacionados con el tratamiento del mensaje: la información no llega de manera oportuna, no es fácil para los 
colaboradores acceder a ella y no siempre es de su interés. Asimismo, la encuesta evidencia que no se está aprovechando adecuadamente el empleo de las imágenes como elementos valiosos e imprescindibles en todo medio de comunicación.

Los altos niveles de indecisión en las respuestas se deben a la falta de información objetiva que los colaboradores perciben en los mensajes de la alta dirección. Si bien manifestaron no tener identificación con las normas, sí expresan una alta filiación con los valores institucionales, lo cual es bastante positivo. Así, la credibilidad de los voceros debe ser aprovechada a fin de fortalecer el diálogo y el debate.

Los colaboradores señalan que el diálogo responde más al interés de la institución y no al de sus necesidades; por tal razón, se reduce la identificación con las políticas institucionales y disminuyen las relaciones colaborativas entre el público interno. Lo rescatable es que existe, en el público interno, el deseo y la voluntad de proponer soluciones. Es necesario mejorar los medios de comunicación ascendente. En suma, El adecuado diagnóstico de la situación organizacional permitirá planificar y ejecutar las estrategias de comunicación que impulsen propuestas de solución tendientes al consenso.

\section{Fuentes consultadas}

Ballenato, G. (2013). Comunicación eficaz. Teoría y práctica de la comunicación humana. Madrid: Pirámide.

Barquero, J. y Barquero, C. (2005). Comunicación estratégica: relaciones públicas, publicidad y marketing. Madrid: McGraw-Hill.

Berlo, D. (2004). El proceso de la comunicación. Bueno Aires: El Ateneo.

Black, S. (2004). El ABC de la Relaciones Públicas. Barcelona: Gestión 2000

Brandolini, A.; González, M. y Hopkins, N. (2009). Comunicación interna. Buenos Aires: Dircom.

Colegio de Relacionistas Públicos del Perú (2015). "Normas legales". Extraída el 26/ VIII/2015 desde http://www.colegioprpperu.org/leyes.htm

Com, S. (comp.) (2011). Introducción a la comunicación. Buenos Aires: Ediciones Aula Taller.

Correa, F. (2014). Administración. Bogotá: El Cid Editor.

Diez, S. (2011). Técnicas de Comunicación. La comunicación en la empresa. Bogotá: Ediciones de la U. 
Fernández, C. y Galguera, L. (2009). Teorías de la comunicación. México D. F.: McGrawHill.

Garrido, L. (2011). “Habermas y la teoría de la acción comunicativa”. Extraída el 1/IX/2015 desde http://www.razonypalabra.org.mx/N/N75/ultimas/38_Garrido_M75.pdf

Goleman, D. (2009). La inteligencia emocional en la empresa. Buenos Aires: El Cid.

Grunig, J. y Hunt, T. (2000). Dirección de Relaciones Públicas. Barcelona: Gestión 2000.

Niño, V.

_(2013). Semiótica y lingüística: fundamentos. Bogotá: Ecoe Ediciones.

_(2002). Semiótica y lingüística: aplicadas al español. Bogotá: Ecoe Ediciones.

Nothstine, W. (1992). Cómo influir en los demás. México D. F.: Iberoamérica.

Otero, E. (1997). Teorías de la Comunicación. Santiago de Chile: Editorial Universitaria.

Pereira, J. y Flores, F. (2010). Relaciones Públicas. Fundamentos, praxis y comunicación corporativa en el Tercer Milenio. Lima: San Marcos.

Rosenberg, M. (2006). Comunicación no violenta: un lenguaje de vida. Buenos Aires: Gran Aldea de Editores.

Simon, R. (2009). Relaciones Públicas. Teoría y práctica. México D. F.: Limusa.

Solórzano, E.

_(2013). "Relaciones Públicas: Aportes científicos de la Escuela Latinoamericana. Memoria Científica: VII Congreso Internacional 'Relaciones Públicas Latinoamericanas: escenarios cambiantes, nuevos desafíos"'. Revista Cientifica de la Asociación Latinoamericana de Carreras Universitarias de Relaciones Públicas, núm. 7, pp. 79-90.

_(2000). "Relación humana, legitimidad y acción comunicacional. Propuestas teóricas y metodológicas de las Relaciones Públicas". Revista Cientifica de la Asociación Latinoamericana de Carreras Universitarias de Relaciones Públicas, núm. 1, pp. 5-11.

Solórzano, E. y Pirotte, A. (2006). Diccionario de uso para Relaciones Públicas. Lima: USMP.

Xifra, J.

_(2010). Relaciones públicas, empresa y sociedad: una aproximación ética. Barcelona: Editorial UOC.

_(2009). Comunicación proactiva: la gestión de conflictos potenciales en las organizaciones. Barcelona: Gedisa. 